

AKADÉMIAI KIADÓ

\title{
Plasma interleukin-6 levels correlate with survival in patients with bacterial sepsis and septic shock
}

\section{Interventional Medicine and Applied Science}

11 (2019) 4, 224-230

DOI:

10.1556/1646.2020.00006

(c) 2019 The Author(s)

\section{RESEARCH ARTICLE}

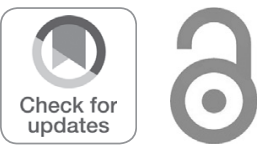

*Corresponding author. Tel.: +57 3217892158; fax: +57 25183000 . E-mail: monikchavez@gmail.com

\author{
MONICA CHAVEZ VIVAS ${ }^{1 *} \odot$, \\ HECTOR FABIO VILLAMARIN GUERRERO ${ }^{2}$, \\ ANTONIO JOSE TASCON ${ }^{3,5}$ and \\ AUGUSTO VALDERRAMA-AGUIRRE ${ }^{4}$
}

\footnotetext{
${ }^{1}$ Health Sciences Faculty, Universidad Libre - Seccional Cali, Campus Valle de Lili, Carrera 109 No. 22 -00 - Valle del Lili A.A. 1040, Santiago de Cali, GIMMEIN Research Group, Cali, Colombia

${ }^{2}$ Physical Therapy-ICU, Fundacion Valle del Lili Av, Simón Bolívar, Cra 98 \# 18-49, Cali, Colombia

${ }^{3}$ Health Sciences Faculty, Universidad Libre - Seccional Cali, Campus Valle de Lili, Carrera 109 No. 22 -00, Cali, Colombia

${ }^{4}$ Biomedical Research Institute, Universidad Santiago de Cali, Campus Pampalinda, Cali, Colombia

${ }^{5}$ Intensive Care Unit, Versalles Clinic, Cali, Colombia
}

Received: May 5, 2019 • Accepted: September 8, 2019

Published online: August 2, 2021

\section{ABSTRACT}

In this study, IL-6 levels were assessed as inflammatory biomarker of bacterial sepsis in patients hospitalized at the ICU of the hospital of Colombia.

Materials and methods: Prospective study on 62 patients diagnosed with sepsis and septic shock. An ELISA assay was used to test serum levels of IL- 6 at admission and $48 \mathrm{~h}$ after admission. Variables were analyzed by $\chi 2$ test (alfa $<0.05)$. Multivariable Cox regression was used to determine the survival with the statistical program SPSS v23.00. Results: Patient's median age was 53 years old and $59.7 \%$ were male. Lung was the most common primary site of infection (43.5\%), and hypertension comorbidity with higher prevalence $(40 \%)$. Infection by Gram negative bacteria were significantly more frequent among patients than Gram positive $(P=0.037)$. Overall, survival analysis showed that $10(16.1 \%)$ patients died with a survival median of $7.00+4.874(2-3)$ days. In patients with sepsis we detected a significant decline in the average of IL-6 serum levels after $48 \mathrm{~h}$ of admission [7.50 (SD: 7.00-68.00) $\mathrm{pg} / \mathrm{mL}$ vs. 68.00 [SD: $7.00-300.00] \mathrm{pg} / \mathrm{mL}(P=0.000)$. Only $25 \%$ of patients with septic shock who presented high levels of IL- 6 at the time of admission and at $48 \mathrm{~h}$ had a survival up to 15 days ( $P$ $=0.005)$. Conclusion: We found significant differences between the plasma levels of IL-6 during the first $48 \mathrm{~h}$ after admission to the ICU among patients with sepsis and septic shock. Patients with sepsis had a significant decline in IL-6 levels, whereas in patients who developed septic shock, levels of this cytokine remained high and have a lower survival compared to those who maintained low levels of IL-6.

\section{KEYWORDS}

interleukin-6, biological markers, sepsis, septic shock, survival

\section{INTRODUCTION}

Sepsis is the most common cause of death among critically ill patients in intensive care units (ICU) in Colombia, with a mortality rate of almost 33.6\% [1-3]. Despite the increasing standard of care and supportive therapy, the challenging problem of sepsis is growing [1]. In sepsis, the inflammatory response to the invading pathogen involves inflammatory and anti- 
inflammatory processes, humoral and cellular reactions and circulatory abnormalities [4]. Cytokines play vital roles in the regulation of host immune response, and altered expression of cytokines is proven to be involved the development of sepsis [5]. Previous research suggests that the variations in the genes encoding cytokines are also involved in the inflammatory responses and are responsible for interindividual differences in susceptibility to sepsis and in its severity [6-9]. These variations influence the plasma levels of cytokines and are related to severity and mortality in patients with sepsis [9-13].

Among these cytokines, IL- 6 is considered to play an important role in the evolution of sepsis, especially as an early indicator of the inflammatory state [14-18]. Several studies have detected nucleotide changes in the gene that codes for IL-6, generating polymorphisms that would be related to risk factors or protectors to develop sepsis, septic shock and even death due to sepsis [16-18].

The search for new biomarkers of high sensitivity and specificity in sepsis is one of the main fields of research. It is clear that the monitoring of the inflammatory biomarker in each patient would allow to identify the acute moment of the disease, to proceed to a timely and individualized treatment and thus reduce the deterioration of the inflammatory response and the fatal outcome [11, 12]. In response, the patient can rapidly evolve favorably, decreasing hospital stays and the negative economic impact that currently represents patients with sepsis in different hospitals [19-21].

We conducted the present study to determine the serum levels of IL-6 in patients with a diagnosis of bacterial sepsis and septic shock who were in the ICU of a clinic in the city of Cali and their association was established as a biomarker of the disease.

\section{MATERIALS AND METHODS}

\section{Study design, site, population and sample size}

A prospective study was carried out at the ICU facilities of Clinica Versalles in Cali, Colombia, between March and November 2017.

\section{Study population}

A total of 62 patients ( 37 men and 25 women) were included during a period of 9 months, with at least two criteria considered as organic failure with the SOFA (Sequential Organ Failure Assessment) scale, at the time of admission and daily during their stay in ICU according to the current criteria defined in the third consensus of sepsis [22].

Patients were then stratified according to the sepsis degree and the septic focus (pulmonary, abdominal, urinary, catheter, skin and soft parts, others unknown [including neurological, as well as endocarditis of infectious origin]). Additionally, we included a control group of 20 patients.

The exclusion criteria considered were: age under 18 years old, pregnancy, therapeutic use of cytokines, heparin or thrombolytics, antibiotics treatment prior to admission, and patients who did not survive more than $24 \mathrm{~h}$.

Dysfunction of the organ systems were defined as any of the following criteria: 1) Renal dysfunction: serum creatinine $>2.0 \mathrm{mg} / \mathrm{dl}$ or urine output $<0.5 \mathrm{~mL} / \mathrm{kg}$ per hour despite adequate fluid resuscitation; 2) Liver dysfunction: serum bilirubin $>2.0 \mathrm{gr} / \mathrm{dl}$, or a threefold increase in serum aminotransferases; 3) Disseminated Intravascular Coagulation (DIC): international normalized ratio (INR) $>1.2$, elevated ddimer, platelet $<100.000 / \mathrm{mm} 3)$; 4) Respiratory insufficiency: $\mathrm{PaO} 2 / \mathrm{FiO} 2$ ratio f200; 5) Hypotension: systolic blood pressure $\mathrm{f} 90 \mathrm{mmHg}$ or the mean arterial blood pressure f70 $\mathrm{mmHg}$ despite adequate fluid and vasopressor resuscitation; 6) Central Nervous System (CNS) dysfunction: acute alteration of the mental status.

\section{Sociodemographic and clinical variables}

Sociodemographic variables included age and gender. Clinical variables included: etiological agent reported, date of admission, comorbidities, and all parameters included in the qSOFA scale were analyzed with frequency distribution and percentages $[10,22]$.

\section{Determination of IL-6 in plasma}

Venous blood samples for the determination of plasma levels of IL- 6 were obtained were obtained at admission and at $48 \mathrm{~h}$ after admission in the ICU.

The blood samples $(100 \mu \mathrm{L})$ were collected in tubes that contained EDTA $(10 \mathrm{mmol} / \mathrm{L})$ to prevent activation of the system of coagulation. The tubes were centrifuged immediately for $10 \mathrm{~min}$ at $3,000 \mathrm{rpm}$, and the plasma was stored in aliquots at $-70{ }^{\circ} \mathrm{C}$.

The measurement of IL- 6 was performed in duplicate in the blood samples by using an enzyme immunoassay with Human Il-6 ELISA kit (Elabscience Biotechnology Inc. USA). The detection range was $7.81-500 \mathrm{pg} / \mathrm{mL}$, with intra and interassay coefficients of variation below 5\%. Readings were carried out in an automated optical Spectramax reader at $450 \mathrm{~nm}$. The sensitivity of the assay was $<2 \mathrm{pg} / \mathrm{mL}$. The serum levels of this cytokine are below the detection limit in healthy subjects. Results were related to a dose-response curve obtained with recombinant human IL- 6 and expressed as picograms per milliliter, normal values of IL- 6 corresponding to $<9.7 \mathrm{pg} / \mathrm{mL}[23]$.

\section{Statistical analysis}

The quantitative variables were: days of hospital stay and plasma levels of IL-6 at admission and at $48 \mathrm{~h}$ after admission in the ICU, with a view to assessing their evolution during patient stay in the ICU were analyzed with measures of central tendency and dispersion as the average and standard deviation (SD), respectively.

The distributions of all continuous variables for normal distribution were tested using the Kolmogorov-Smirnov test. For normally distributed variables, mean and standard deviation were used, for non-normally distributed variables 
median and 25th-75th percentiles were used. Comparison of the quantitative variables was carried out using the MannWhitney $U$-test, while categorical variables were compared between groups with the de $\chi^{2}$ test, with a $P$-value $<0.05$ that was considered statistically significant. Correlations between variables were determined by using the Pearson correlation analysis for normally distributed variables, and by the Wilcoxon correlation analysis for IL-6 at time admission and IL-6 at $48 \mathrm{~h}$ in patients with sepsis and septic shock.

Survival was analyzed with Cox regression analysis of patients with sepsis and shock septic, including the covariates: age, primary site of infection and high levels of IL-6 during the stay in the ICU. Logistic regression analysis was also used to estimate Odds Ratio (OR), expressed with their 95\% confidence intervals (95\% CI) for sepsis outcome in relation to levels of IL-6. These analyzes were performed using the statistical package SPSS Vs 23.00 (Inc, Chicago, USA).

\section{Ethical issues}

This study and the protocols related were endorsed by the Ethics Committee of Clinica Versalles (Act No. 05-013). All patients or legal representatives were sufficiently informed about goals and procedures. Samples and data were obtained after written informed consent was signed. The study complied with the provisions of the Helsinki Declaration and the technical and administrative scientific standards for research in health referred to in the "Resolution 8430 of 1993 " of the Ministry of Health.

\section{RESULTS}

Table 1 shows Patients' main characteristics. Overall, the median age was 53 years, $69.4 \%$ patients were diagnosed with sepsis and $30.6 \%$ with septic shock. Age and median ICU stay showed a tendency to be higher in the septic shock subgroup. The qSOFA $>2$ score was more prevalent in the septic shock subgroup. However, none of these variables showed significant differences.

The most prevalent primary site of infection was lung (43.5\%), $41.9 \%$ of patients had hypertension, and the most common organ dysfunction that developed during sepsis was respiratory failure $(16.1 \%)$. Microorganisms were isolated in 45 out of 62 septic patients $(72.6 \%)$, with a predominance of Gram-negative bacteria (59.7\%). Escherichia coli $(15.9 \%)$ and Pseudomonas aeruginosa (11.3\%) were the most common pathogens identified from blood culture.

A total of 52 (83.9\% of the total) patients survived and 10 (16.1\%) died. Demographic, Coexisting diseases and organ dysfunction did not differ significantly between survivors and non-survivors. We only found that infection by Gram negative bacteria was significant among the patients who survived with exact $P$-value of 0.037 .

In addition, the degree of sepsis exerted a strong influence upon mortality; in this context, the patients with septic shock suffered greater mortality $(60 \%)$ and showed a higher probability of death (OR: $4.500 ; \mathrm{CI} \% \min =1.096$, $\max =$ 18.474; $P=0.028)$.

Serum IL-6 levels for healthy individuals were undetectable or $<8.12 \mathrm{pg} / \mathrm{mL}$. The median level of serum IL-6 was 68.00 [7.00-300.0] $\mathrm{pg} / \mathrm{mL}$, whereas that at $48 \mathrm{~h}$ after admission significant decline to $7.50[7.00-68.00] \mathrm{pg} / \mathrm{mL}$ $(P \leq 0.001)$.

On admission, patients with sepsis and septic shock have higher levels of IL- 6 in the serum than that did controls, but the difference was not statistically significant $(P>0.05)$.

We compared IL-6 concentrations among patients with sepsis and septic shock, and observed that baseline serum levels of IL-6 remained high in patients who developed shock during the first $48 \mathrm{~h}$ after admission $(P=0.001)$, and a significant decline in serum IL-6 levels, was observed in patients with sepsis $(P=0.002)$ (data no shown).

The median level of serum IL-6 in non-survivors (125.00 [14.00-250.0] $\rho \mathrm{g} / \mathrm{mL}$ ) was rather higher than that in survivors $(68.00[7.00-300.0] \rho \mathrm{g} / \mathrm{mL})$ at admission, and decline at $14.00[7-81.25] \rho \mathrm{g} / \mathrm{mL}$ in non-survivors and at 7.00 [7.00$63.25] \rho \mathrm{g} / \mathrm{mL}$ at $48 \mathrm{~h}$ after admission. However, there were no significant differences in baseline serum levels of IL- 6 between survivors and non-survivors $(P>0.05)$.

Table 2 shows patients stratified according to low and high serum levels of IL- 6 taken at the time of admission to the ICU. The median in the group High IL-6 was 270.48 [112.5-395.0] $\mathrm{pg} / \mathrm{mL}$ and in in the group Low IL-6 was 7.50 [7-14.00] pg/mL. The prevalence of soft tissue infections

Table 1. Demographic data and serum levels of IL-6 at admission and $48 \mathrm{~h}$ after of admission in patients

\begin{tabular}{lcccc}
\hline & All $(n=62)$ & Sepsis $(n=43)$ & Septic shock $(n=19)$ & $P$-value \\
\hline Gender M/F & $37 / 25$ & $26 / 17$ & $11 / 8$ & 0.849 \\
Age, mean \pm SD & $53.00+19.47$ & $51.93 \pm 20.258$ & $52.21 \pm 18.109$ & 0.921 \\
Days of ICU stay, median \pm SD & $7.00 \pm 4.874(2-3)$ & $7.85 \pm 3.804(2-16)$ & $9.53 \pm 6.703(3-33)$ & 0.544 \\
qSOFA $\geq 2$ (\%) & $23(37.1)$ & $15(34.9)$ & $8(42.1)$ & 0.587 \\
IL-6 pg/mL Admission & $68.00[7.00-300.0]$ & $60.00[7-300]$ & $70.00[30-300]$ & 0.247 \\
$\quad[25$ th-75th percentile] & $7.50[7.00-68.00]$ & $7.00[7-230]$ & $50.00[7-200]$ & 0.215 \\
IL-6 48 h pg/mL & & & & \\
$\quad[25$ th-75th percentiles] & & & \\
\hline
\end{tabular}

Numbers are presented as mean \pm standard deviation or median [25\%-75\%].

$\mathrm{M}$, male; F, female. ICU: intensive care unit. 
Table 2. Characteristics of patients with low $(n=29)$ and high $(n=33)$ plasma levels of interleukin-6 (IL-6) in moment of admission

\begin{tabular}{|c|c|c|c|c|}
\hline Characteristic & Total & High IL-6 n (\%) & Low IL-6 n (\%) & $P$-value \\
\hline \multicolumn{5}{|c|}{ Primary site of infection } \\
\hline Lung & $27(43.5)$ & $16(48.5)$ & $11(37.9)$ & 0.403 \\
\hline Urinary tract & $12(19.4)$ & $7(21.2)$ & $5(17.2)$ & 0.693 \\
\hline Abdomen & $18(29)$ & $6(31.6)$ & $12(27.9)$ & 0.769 \\
\hline Soft tissue infections & $4(6.5)$ & $3(15.8)$ & $1(2.3)$ & $0.047^{*}$ \\
\hline Multiple sites of infection & $3(4.8)$ & $3(9.1)$ & 0 & 0.096 \\
\hline Unknown foci & $4(6.5)$ & 0 & $4(13.8)$ & $0.027^{*}$ \\
\hline \multicolumn{5}{|c|}{ Outcomes } \\
\hline Sepsis & $43(69.4)$ & $22(66.7)$ & $21(72.4)$ & 0.624 \\
\hline Shock septic & $19(30.6)$ & $11(33.3)$ & $8(27.6)$ & \\
\hline Survivors & $52(83.9)$ & $15(78.9)$ & $37(86.0)$ & 0.484 \\
\hline Non-survivors & $10(16.1)$ & $4(21.1)$ & $6(14.0)$ & \\
\hline \multicolumn{5}{|c|}{ Length of ICU stay ${ }^{\psi}$} \\
\hline$\geq 7$ days & $37(59.7)$ & $18(54.5)$ & $19(65.5)$ & 0.380 \\
\hline$<7$ days & $25(40.3)$ & $15(45.5)$ & $10(34.5)$ & \\
\hline
\end{tabular}

*Significant difference, $P<0.05$.

${ }^{\psi}$ Only in survivors.

was significantly higher in the group high IL-6 (15.8\%) than in the group low IL-6 (2.3\%) $(P=0.047)$. No correlation was observed between plasma levels of IL- 6 with organic dysfunction or the type of microorganisms isolated.

Although there is a slightly higher number of individuals who developed septic shock (33.3\%) and non-survivors (21.1\%) with high levels of cytokine, it is not statistically significant.

Significant correlation was seen between high serum levels of IL- 6 during $48 \mathrm{~h}$ after admission and duration of stay in the ICU in patients with shock septic, including age and site of infection as covariates. We found that than only $25 \%$ of these patients who presented high levels of IL-6 at the time of admission and at $48 \mathrm{~h}$ had a survival up to 15 days $(P=0.005$; Fig. 1$)$.

\section{DISCUSSION}

We found a mean age of 53 years equivalent of 52 years found in the previous nationwide report from Colombia $[1,3]$ and other countries [24, 25].

The predominant source of infection was pulmonary (43.5\%) among the infectious sources of sepsis in our patients, followed by abdominal and urosepsis. Similar results were found in the Europa [26, 27] and U.S [28]. Mayr et al.,

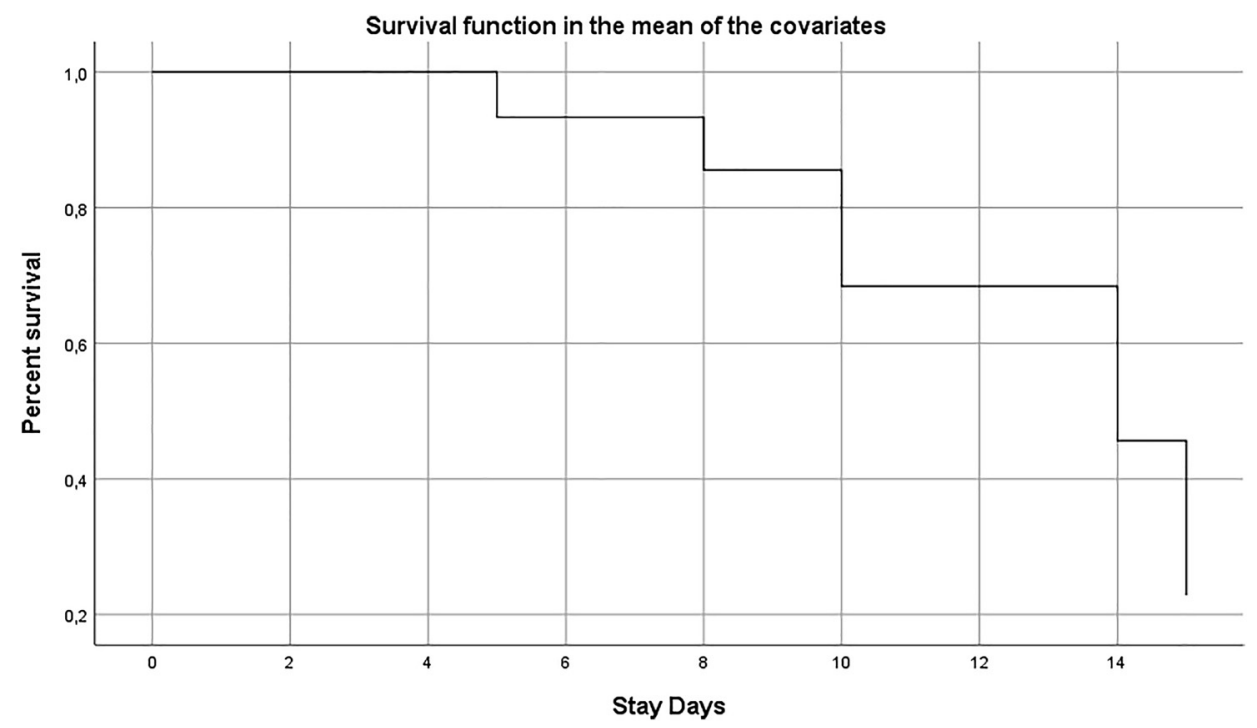

Figure 1. Plasma IL-6 levels of patients with shock septic and correlation with mortality. Patients were divided into those with IL-6 levels greater than $8.12 \mathrm{pg} / \mathrm{mL}(n=11)$ or less than $8.12 \mathrm{pg} / \mathrm{Ll}(n=8)$. Patients with higher levels of plasma IL-6 had significantly greater mortality, only $25 \%$ of these patients who presented high levels of IL- 6 during the $48 \mathrm{~h}$ after admission had a survival up to 15 days. $P=0.005$ by analysis survival cox regression 
found that respiratory tract infections, particularly pneumonia, are the most common site of infection, and associated with the highest mortality [29]. However, we found a lower presence of organ dysfunctions among our patients compared to previous reports [24, 25, 29].

Gram-negative bacteria constituted $59.7 \%$ of the positive cultures, the prevalence of Gram-positive bacteria was lower (12.9\%), these results agree with those obtained by Ortíz et al., who found that the main source of infections in patients with sepsis they were due to Gram negative bacteria (68\%), while Gram positive organisms only constituted $30 \%$.

The mean length of ICU stay in our study was 7.00 (2-16) days and of patients with septic shock of 10.00 (3-33) days. The duration of ICU stay in our study was comparable to Ortiz et al. study of 10 (5-25) days in patients with severe sepsis [1].

The mortality observed in our study was of $16.1 \%$. This is in sharp contrast with mortality in others colombian studies rate ranging from $22 \%$ (3) to $33 \%$ [1], which increased to $46 \%$ for patients in the ICU with septic shock [3]. However, consistent with other similar recent international studies, hospital mortality for sepsis admissions was $19.4 \%$ in Norway [27], 8.9\% in the U.S [30]. In addition, we found that a significant number of patients who survived and died were infected with Gram-negative bacteria $(P<0.05)$. Evidence suggests that a patient respond differently to lipopolysaccharide (LPS) of Gram-negative bacteria and lipoteichoic acid (LTA) of Gram-positive bacteria what induces what induces in a differential inflammatory pattern during sepsis [31-33].

As pointed out above, serum levels of IL-6 are well known to be involved in sepsis pathogenesis and take part in the systemic response to infection [11-17].

This study was aimed at assessing the levels of IL- 6 in the blood serum of patients with sepsis and septic shock. The results demonstrated significant decline of IL-6 at $48 \mathrm{~h}$ after the pharmacotherapy of systemic infection compared with their initially high levels at the at the time of admission to the intensive care unit (Table 1). These observations may be confirmed with other reports $[15,17,34-38]$. In the case of patients with septic shock, the levels of IL-6 in blood serum remained high during the first $48 \mathrm{~h}$ after admission to the ICU $(70.0 \mathrm{pg} / \mathrm{mL}$ at admission; $50.0 \mathrm{pg} / \mathrm{mL}$ at $48 \mathrm{~h})$, compared to septic patients $(60.0 \mathrm{pg} / \mathrm{mL}$ at admission; $7.0 \mathrm{pg} / \mathrm{mL}$ at $48 \mathrm{~h}$ ), this may indicate additional anti-inflammatory mechanisms involved in the course of infection, perhaps due to increased damage of the endothelium in patients with septic shock. Increased levels of IL6 have also been found by other investigators in septic shock [36, 37]. Gentile et al., suggest that serum levels of IL- 6 in sepsis are elevated early, identifying patients at a risk of developing severe sepsis, indicating that the main role of IL- 6 in sepsis is prognostic, not diagnostic [36].

We found that serum levels of IL-6 discriminated early between non-survivors and survivors, with cut-off values of $125.0 \mathrm{pg} / \mathrm{mL}$ and $68.0 \mathrm{pg} / \mathrm{mL}$ at admittance, respectively. In the patients who survived, IL- 6 concentration decreased steadily, and at day 2, they reached $89.7 \%$ reduction from baseline levels. Mortality rate was higher for patients with high levels of IL-6 $(21.1 \%)$ at $0 \mathrm{~h}$ in comparison to patients with Low levels (14.0\%) although not statistically significant $(P=0.484)$.

Studies suggest that serum levels of IL-6 in patients with sepsis are elevated in non-survivors and are associated with early mortality [35-38]. In our study we did not find a significant correlation between serum levels of IL-6 and sepsis outcome in terms of mortality.

As shown in Table 2, levels of IL-6 were not associated with common coexisting diseases, organ dysfunction or Length of ICU stay. Although patients with soft tissue infections presented significantly higher levels of IL-6, it is necessary to increase the number of patients to confirm this result.

We found that $68.4 \%$ of patients infected with Gramnegative bacteria had high levels of IL-6. The pattern production of IL-6 can be different in Gram-positive and Gramnegative infections. The levels of IL- 6 are higher in the plasma of patients with sepsis induced by Gram-positive bacteria than in patients with sepsis induced by Gramnegative bacteria as some studies have shown [38, 39]. Contradictory results have been obtained in other studies, which have established an increase in the levels of IL-6 induced by the LPS [39].

In this study it was possible to demonstrate that patients with septic shock who presented high levels of IL-6 have a lower survival compared to those who maintained low levels of IL-6.

In conclusion, we found significant differences between the plasma levels of IL- 6 during the first $48 \mathrm{~h}$ after admission to the ICU among patients with sepsis and septic shock. Patients with sepsis had a significant decline in IL-6 levels, whereas in patients who developed septic shock, levels of this cytokine remained high and have a lower survival However, more studies are needed, including a larger number of patients with septic shock to establish whether IL-6 concentrations can discriminate early between survivor and non-survivor septic shock patients, and might be used as prognostic parameters in the future.

Funding sources: This study was funded by Clinica Versalles de Cali.

Authors' contribution: All the authors contributed in planning, conduct, and reporting of the work. They also had full access to all data in the study and take responsibility for the integrity of the data and the accuracy of the data analysis.

Conflict of interest: All authors declare no conflict of interest.

\section{REFERENCES}

[1] Ortiz G, Dueñas C, Rodríguez F, Barrera L, De la Rosa. Dennis R. Epidemiology of sepsis in Colombian intensive care units. Biomédica 2014;34:40-7. 
[2] Jaramillo-Bustamante JC, Marín-Agudelo A, Fernández-Laverde $M$, Bareño-Silva J. Epidemiology of sepsis in pediatric intensive care units: first Colombian multicenter study. Pediatr Crit Care Med 2012;13(5):501-8.

[3] Rodriguez F, Barrera L, De la Rosa G, Dennis R, Dueñas C, Granados M, et al. The epidemiology of sepsis in Colombia: a prospective multicenter cohort study in ten university hospitals Crit Care Med 2011;39(7):1675-82.

[4] Kaukonen K-M, Bailey M, Pilcher D, Cooper DJ, Bellomo R. Systemic inflammatory response syndrome criteria in defining severe sepsis. N Engl J Med 2015;372(17):1629-38.

[5] Schulte W, Bernhagen J, Bucala R. Cytokines in sepsis: potent immunoregulators and potential therapeutic targets-an updated view. Mediators Inflamm 2013;Article ID 165974:16. http://doi. org/10.1155/2013/165974.

[6] Tumangger H, Jamil KF. Contribution of genes polymorphism to susceptibility and outcome of sepsis. Egyp J Med Hum Gen 2010; 11:97-103.

[7] Ahrens P, Kattner E, Kohler B, Hartel C, Seidenberg J, Segerer H. Mutations of genes involved in the innate immune system as predictors of sepsis in very low birth weight infants. Pediatr Res 2004;55: 652-6.

[8] Stuber F, Klaschik S, Lehmann LE, Schewe JC, Weber S, Book M. Cytokine promoter polymorphisms in severe sepsis. Clin Infect Dis 2005;41(Suppl7):S416-20. http://doi.org/dqr3gs.

[9] Bozza FA, Salluh JI, Japiassu AM, Soares M, Assis EF, Gomes RN, et al. Cytokine profiles as markers of disease severity in sepsis: a multiplex analysis. Crit Care 2007;11(2):R49. http://doi.org/ c5vg76.

[10] Wiersinga WJ, Leopold SJ, Cranendonk DR, van der Poll T. Host innate immune responses to sepsis. Virulence 2014;5(1):36-44.

[11] Marshall JC, Reinhart K: Biomarkers of sepsis. Crit Care Med 2009;37:2290-8.

[12] Pierrakos C, Vincent J-L. Sepsis biomarkers: a review. Crit Care 2010;14:R15. https://doi.org/10.1186/cc8872.

[13] Faix JD. Biomarkers of sepsis. Crit Rev Clin Lab Sci 2013;50(1): 23-36. http://doi.org/bwk5.

[14] Fink MP. The prevention and treatment of sepsis: is interleukin-6 a drug target or a drug? Crit Care Med 2006 Mar;34(3):919-21.

[15] Papanicolaou DA, Wilder RL, Manolagas SC, Chrousos GP. The pathophysiologic roles of interleukin-6 in human disease. Ann Intern Med 1998 Jan;128(2):127-37.

[16] Martín-Loeches I, Violan JS, Blanquer J, Aspa J, Rodríguez-Gallego C, Rodríguez-de Castro F, et al. Effect of the IL-6 promoter polymorphism -174 G/C on risk and outcome of pneumonia. Crit Care 2008;12(Suppl 2):P465. http://doi.org/fk94tw.

[17] Sutherland AM, Walley KR, Manocha S, Russell JA. The association of interleukin 6 haplotype clades with mortality in critically ill adults. Arch Intern Med 2005 Jan 10;165(1):75-82.

[18] Tischendorf JJW, Yagmur E, Scholten D, Vidacek D, Koch A, Winograd R, et al. The interleukin-6 (IL6)- 174 G/C promoter genotype is associated with the presence of septic choque and the ex vivo secretion of IL6. Int J Immunogenet 2007 Dec;34(6):413-8.

[19] Angus DC. The lingering consequences of sepsis: a hidden public health disaster? JAMA 2010;304:1833-4.

[20] Tanriover M. Epidemiology and outcome of sepsis in a tertiarycare hospital in a developing country. Epidemiol Infect 2006;134: $315-22$.
[21] Boussekey N, Cantrel J, Debrabant LD, Langlois J, Devos P, Meybeck A, et al. Epidemiology, prognosis, and evolution of management of septic choque in a French intensive care unit: a five years survey 2010; Article ID 436427:7.

[22] Singer M, Deutschman CS, Seymour C, Shankar-Hari M, Annane $\mathrm{D}$, Bauer $\mathrm{M}$, et al. The third international consensus definitions for sepsis and septic choque (Sepsis-3). JAMA 2016;315(8):801-10. https://doi.org/10.1001/jama.2016.0287.

[23] Nemzek JA, Sidiqui J, Remick DG. Development and optimization of cytokine ELISAs using commercial antibody pairs. J Immunol Methods 2001;255:149-57.

[24] Bouza C, Lopez-Cuadrado T, Saz-Parkinson Z, Amate-Blanco JM. Epidemiology and recent trends of severe sepsis in Spain: a nationwide population-based analysis (2006-2011). BMC Infect Dis 2014;14:3863;PMID:25528662.

[25] Zimmerman JE, Kramer AA, Knaus WA. Changes in hospital mortality for United States intensive care unit admissions from 1988 to 2012. Crit Car 2013;17:R81;PMID:23622086. http://doi. org/10.1186/cc12695.

[26] SepNet Critical Care Trials G. Incidence of severe sepsis and septic shock in German intensive care units: the prospective, multicentre INSEP study. Intensive Care Med 2016;42(12):1980-9;PMID: 27686355.

[27] Knoop ST, Skred S, Langeland N, Flaatten HK Epidemiology and impact on all-cause mortality of sepsis in Norwegian hospitals: a national retrospective study. Plos One;2017:17. https://doi.org/10. 1371/journal.pone.0187990.

[28] Martin GS, Mannino DM, Eaton S, Moss M. The epidemiology of sepsis in the United States from 1979 through 2000. N Engl J Med 2003;348:1546-54;PMID:12700374. http://dx.doi.org/10.1056/ NEJMoa022139.

[29] Mayr FB, Yende S, Angus DC. Epidemiology of severe sepsis. Virulence 2014;5(1):4-11.

[30] Wang HE, Szychowski JM, Griffin R, Safford MM, Shapiro NI, Howard G. Long-term mortality after community acquired sepsis: a longitudinal population-based cohort study. BMJ Open 2014;4:e004283. https://doi.org/10.1136/bmjopen2013-004283.

[31] Kumar H, Kawai T, Akira S. Pathogen recognition by the innate immune system. Int Rev Immunol 2011;30:16-34.

[32] Legrand M, Klijn E, Payen D, Ince K. The response of the host microcirculation to bacterial sepsis: does the pathogen matter? J Mol Med 2010;88:127-33.

[33] Remick DG, Bolgos G, Copeland S, Siddiqui J. Role of interleukin6 in mortality from and physiologic response to sepsis. Infect Imm 2005;73(5):2751-7.

[34] Lukaszewski RA, Yates AM, Jackson MC, Swingler K, Scherer JM, Simpson AJ, et al. Presymptomatic prediction of sepsis in intensive care unit patients. Clin Vaccin Immunol 2008;15(7):1089-94. https://doi.org/10.1128/CVI.00486-07.

[35] Carta A, de Lucca MG, Pires MD, Lobo SM. Sepsis-associated organ dysfunction and increased supportive care are associated with high serum interleukin-6 levels J Bras Patol Med Lab 2016; 52(6):367-73.

[36] Gentile LF, Cuenca AG, Vanzant EL, Efron PA, McKinley B, Moore $\mathrm{F}$, et al. Is there value in plasma cytokine measurements in patients with severe trauma and sepsis? Methods 2013;61:3-9. https://doi.org/10.1016/j.ymeth.2013.04.024. 
[37] Cioara A, Valeanu M, Todor N, Cristea V, Lupse M. Early sepsis biomarkers and their relation to mortality. Rom J Anaesth Intensive Care 2016;23(2):159-60.

[38] Andaluz-Ojeda D, Bobillo F, Iglesias V, Almansa R, Rico L, Gandía F, et al. A combined score of pro- and anti-inflammatory interleukins improves mortality prediction in severe sepsis.
Cytokine 2012;57:332-6. https://doi.org/10.1016/j.cyto.2011.12. 002.

[39] Surbatovic M, Popovic N, Vojvodic D, Milosevic I, Cimovic GA, Milan Stojicic M, et al. Cytokine profile in severe gram positive and gram-negative abdominal sepsis. Sci Rep 2005;5:11355. https://doi.org/10.1038/srep11355. 